\title{
PRELIMINARY LONG-PERIOD MAGNETOTELLURIC INVESTIGATION AT THE EDGE OF ICE SHEET IN EAST ANTARCTICA
}

\author{
Jingxue Guo ${ }^{1}$, Kun Wang ${ }^{2,3^{*}}$,Zhaofa Zeng ${ }^{3}, \operatorname{Lin~Li}^{1}{ }^{1}$ Juncheng Liu ${ }^{1,3}$,Xueyuan Tang ${ }^{1}$,Xiangbin Cui ${ }^{1}$,Yinze Wang ${ }^{4}$, Bo Sun $^{1}$,Junming \\ Zhang $^{2}$ \\ ${ }^{1}$ Polar Research Institute of China, Shanghai 200136 China- (guojingxue, lilin, liujuncheng, tangxueyuan, cuixiangbin, sunbo) \\ @ pric.gov.cn \\ ${ }^{2}$ College of Energy and Mining Engineering, Shandong University of Science and Technology, Qingdao 266590 China- \\ wkun@sdust.edu.cn; truegis@163.com \\ ${ }^{3}$ College of Geo-exploration Science and Technology, Jilin University, Changchun, 130026China-zengzf@jlu.edu.cn \\ ${ }^{4}$ Beijing Orangelamp Geophysical Exploration Co.,Ltd, Beiing 102200, China - wyz@orangelamp.cn
}

KEY WORDS: Antarctica, Geophysical exploration, Long-period magnetotelluric, Mantle structure

\begin{abstract}
:
The lithospheric mantle structure of the Antarctic continent is of great significance of studying the polymerization and fragmentation mechanism of Gondwana and the plate movement law. Long-period magnetotelluric(LMT) is an important method to study the electrical structure of earth crust and mantle. However, been limited by the bad natural environment and logistics supply difficulties, there is no LMT record of Antarctica before. In 2018, China's 34th Antarctic scientific expedition carried out the LMT survey at the eastern edge of the Antarctic continent with a frequency range of $0.00015 \mathrm{~Hz}$ to $0.1 \mathrm{~Hz}$. After the processing and analysis, we get three points as fellow: (1) The lithospheric mantle of Antarctica has a three-dimensional resistivity structure; (2) There are low resistivity regions in the Antarctic mantle, which may be related to thermal activity. (3) It is possible to carry out LMT measurements in eastern Antarctic and more can be done in the future.
\end{abstract}

\section{INTRODUCTION}

The Antarctic continent are the central block of all the fragmented blocks of Gondwana, which is adjacent to other blocks(such as Africa, India, and Australia) before the disintegration of Gondwana in the late Mesozoic(An et al., 2015; Torsvik et al., 2010). Since the Mesozoic, the level of tectonic activity in the Antarctic continent is relatively low, especially in the stable craton in the east of the Antarctic continent which is no obvious tectonic deformation in the crust or lithosphere(An et al., 2015; Cande et al., 2000). The information on the aggregation and evolution of Gondwana ancient land may still be preserved in its crust and lithospheric mantle. Therefore, the lithospheric mantle structure of the Antarctic continent is of great significance of studying the polymerization and fragmentation mechanism of Gondwana and the plate movement law(Michaux, 2009; Sutherland and Cooper, 2008).

To research, the lithospheric mantle structure largely depends on geophysical methods(Darbyshire et al., 2018; Malleswari et al., 2019; Tian et al., 2016; Winberry and Anandakrishnan, 2004). Magnetotelluric(MT) is an important geophysical technique for investigating sub-ice structure of Antarctica, which has the advantages of wide detection frequency band, not easy to be shielded by high resistivity layer, high resolution to low resistivity abnormal body, simple field construction layout and minimal environmental impact(Peacock and Selway, 2016). Hessler and Jacobs (1966) described the MT measurement in Antarctica first. Based on the analysis of two MT data collected from North Victoria Land, Antarctica, Beblo and Liebig (1990) believe that the non-plane wave field source of the polar region has little influence on the calculation of MT apparent resistivity. Wannamaker et al. (1996) overcome the problem of high contact resistance through preamplifier and obtained the highquality MT data in the middle thick ice-covered area of Byrd subglacial basin in Antarctica at first time. In 2004, they also collected high-quality MT data onto the eastern Antarctica, which proved the feasibility of MT data collection of the whole Antarctic region(Wannamaker et al., 2004). After that, Armadillo et al. (2004), Murthy et al. (2013), Peacock and Selway (2016) also showed the excellent MT measurement at the eastern Antarctica (Figure 1). Long-period magnetotelluric (LMT) can be used to study the electrical structure of earth crust and mantle(Lizarralde et al., 1995; Mackie et al., 1988; Unsworth et al., 2005).

However, due to the fact that Antarctica is covered by ice and snow, limited by the bad natural environment and logistics supply difficulties, it is relatively difficult to carry out largescale long-time MT measurement continuously. At present, the most detection depth is generally within $40 \mathrm{kms}$ using MT method(Armadillo et al., 2004; Murthy et al., 2013; Peacock and Selway, 2016; Wannamaker et al., 2004). The geophysical research on the structure of the Antarctic plate crust and lithospheric mantle is still focused on imaging the broadband seismic base station data(An et al., 2015; Heeszel et al., 2016; Ritzwoller et al., 2001), processing and inversion of satellite gravity anomaly data(Haeger et al., 2019; Ji et al., 2018; Scheinert et al., 2016), and joint processing and interpretation based on gravity and seismic data(Baranov et al., 2017; Tenzer et al., 2018).

This paper introduces the LMT measurement of China's 34th Antarctic expedition to 2018 at the edge of ice sheet in east antarctica. The purpose of this work is to test the feasibility of LMT measurement of Antarctica. Using the LMT data, we can obtain the electrical structure of the upper mantle of the lithosphere and enriches the geophysical data set about the Antarctic lithospheric mantle structure. Considering the issue of logistics supplied, prior to the more challenging polar inland

\footnotetext{
${ }^{*}$ Corresponding author.
} 
survey, the LMT sites were set near Zhongshan Station this time (Shown in Figure 1.).

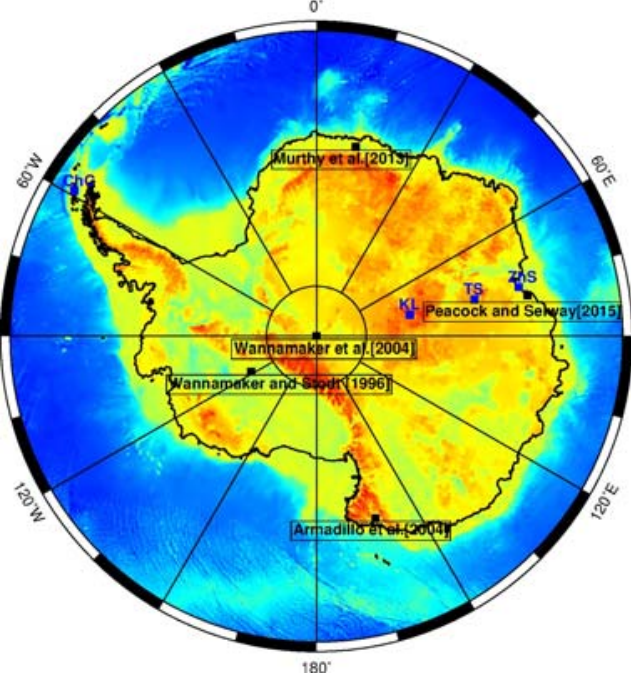

Figure 1. Topographic map of Antarctic. The blue rectangle mark is located at China Investigation station, ZHS: Zhongshan Station; TS: Taishan station; KL:

Kunlun station; CHC: Great Wall Station. The black rectangle marks where MT measurements have been carried out.

\section{LMT METHOD}

MT is a passive method that measures the Earth's electrical response to natural, time-varying magnetic fields(Chave and Jones, 2012). And there is a key assumption that the magnetic field is a horizontally polarized plane wave propagating vertically to the earth in MT method. The plane waves electromagnetic field satisfies the Maxwell equations as follows:

$$
\left\{\begin{array}{c}
\nabla \times \mathbf{H}=\mathbf{j}+\frac{\partial \mathbf{D}}{\partial t} \\
\nabla \times \mathbf{E}=-\frac{\partial \mathbf{B}}{\partial t} \\
\nabla \bullet \mathbf{B}=0 \\
\nabla \bullet \mathbf{D}=q
\end{array}\right.
$$

where $\mathbf{H}=$ the magnetic field strength $(\mathrm{A} / \mathrm{m})$

$\mathbf{E}=$ the electric field strength $(\mathrm{V} / \mathrm{m})$

$\mathbf{D}=$ the electrical $\operatorname{displacement}\left(\mathrm{C} / \mathrm{m}^{2}\right)$

$\mathbf{B}=$ the magnetic induction intensity $\left(\mathrm{Wb} / \mathrm{m}^{2}\right)$

$\mathbf{j}=$ the conduction current $\operatorname{den} \operatorname{sity}\left(\mathrm{A} / \mathrm{m}^{2}\right)$

$\frac{\partial \mathbf{D}}{\partial \mathrm{t}}=$ the displacement current density.

Moreover, based on the Maxwell equation, the $\mathbf{H}$ and $\mathbf{E}$ measured at the surface satisfy the following relationship:

$$
\mathbf{E}=\mathbf{Z H}
$$

where $\mathbf{Z}$ is the impedance tensor, also been called the MT transfer function. $\mathbf{Z}$ is a complex, frequency-dependent, rank two tensor that contains all the information about subsurface resistivity structure(Peacock and Selway, 2016).

$$
\mathbf{Z}=\left(\begin{array}{ll}
Z_{x x} & Z_{x y} \\
Z_{y x} & Z_{y y}
\end{array}\right)
$$

In a 1-D Earth model, the diagonal components of $\mathbf{Z}$ will be zero and the off-diagonal components will be equal but opposite in sign; In a 2-D Earth model, when the measured $\mathrm{E}$ and $\mathrm{H}$ fields are parallel and perpendicular to geoelectric strike, the diagonal components of $\mathbf{Z}$ will remain zero while the offdiagonal components will decompose into the transverse electric (TE) mode and the transverse magnetic (TM) mode. In a 3D Earth model, , all components of $\mathbf{Z}$ will be nonzero (Booker, 2014; Peacock and Selway, 2016). Therefore, before the inversion of MT data, dimension analysis is needed to determine the correct earth model(Bahr, 1988; Martí, 2014).

There is no essential difference between the method of LMT and MT. In MT method, the penetration depth can be estimated by the skin depth, which increases with period and subsurface resistivity. Therefore, the LMT method can penetrate a deeper structure than the general MT method. Accordingly, in order to obtain long-period data, the LMT method requires a longer acquisition time, which is particularly difficult in Antarctica.

\section{DATA RECORDING}

From November 15, 2017 to February 5, 2018, Eight longperiod magneto telluric survey points were sit by Polar Research Institute of China within $20 \mathrm{~km}$ south of Zhongshan station, Antarctica (Shown in Figure 2.). An Aether multifunctional acquisition system was used for data recording developed by Crystal Globe (Shown in Figure 3). Magnetic fields $(\mathrm{Bx}, \mathrm{By}, \mathrm{Bz})$ were measured using three-component fluxgate sensor (Shown in Figure 3.c). Electric fields were measured using non-polarizing electrode (Shown in Figure 3.b). Horizontal electric (Ex, Ey) and magnetic (Bx, By) field components were recorded in N-S and E-W orientation. For each station, the total recording time was 144-168 hours. The control and detection of the acquisition status is completed by the acquisition software on the external PC (Shown in Figure 3.a).

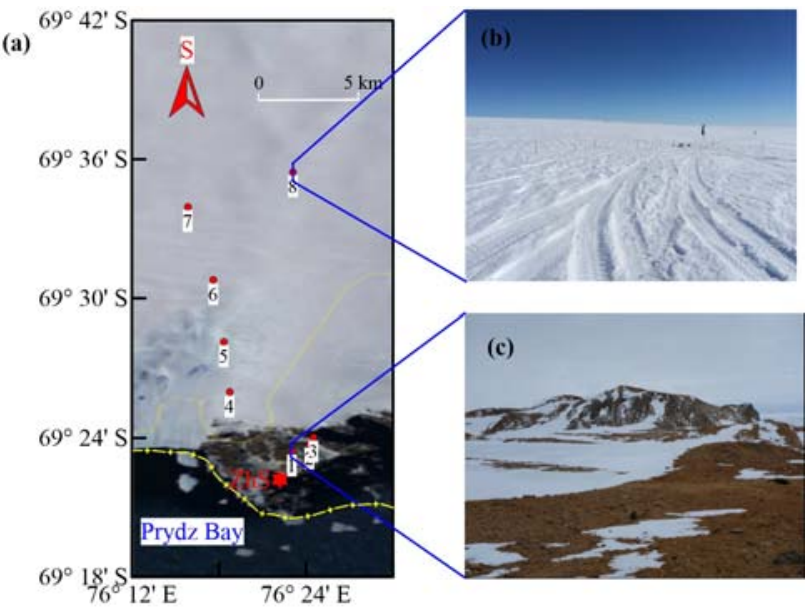

Figure 2. (a)Location map of LMT survey stations on the Antarctic continent, with the location of Zhongshan Station marked in red hexagon, and the red solid point as the survey point; (b)Landform photo of the 8th LMT station; (c)Landform photo of the 1th LMT station. 
Since the electromagnetic field time series recording by Aether are stored in blocks, before further processing, we used the Geotshub software matched with Aether to merge the time series blocks into a single time series file. Then, impedance tensors were estimated at time series using the proprietary prMT software from Crystal Globe with local electric field (E) reference. with a period range of 13-6700 s. According to Equation(4), the apparent resistivity can be calculated(Nam et al., 2007):

$$
\rho_{a}^{i j}(\varpi)=\frac{1}{\mu_{0} \varpi}\left|Z^{i j}(\varpi)\right|^{2}
$$

where

$$
\begin{aligned}
& \omega=\text { the angular frequency } \\
& \mu_{0}=\text { the free space permeability } \\
& Z^{i j}=\text { the impedance tensor element } \\
& \rho_{a}^{i j}=\text { the apparent resistivity. }
\end{aligned}
$$

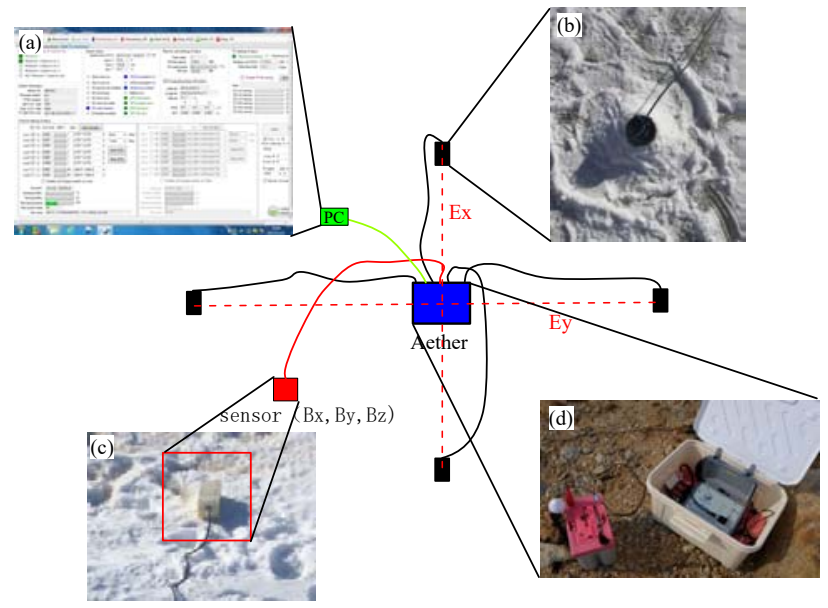

Figure 3. Aether multi-functional acquisition system.

(a)control software; (b) non-polarizing electrode;(c) threecomponent fluxgate sensor; (d) Aether host.

\section{DATA ANALYSIS AND INVERSION}

Before the LMT data inversion, the geometric characteristics of subsurface geological structures should be identified. 2D skewness and geo-electrical strike could describe this geometric characteristic(Lilley, 1998). We used Bahr impedance tensor decomposition technique to obtain 2D skewness and geoelectrical strike(Bahr, 1988).

Generally, 2D skewness could reflect the special extension characteristic of subsurface geological structure(Schaa et al., 2018). When its value is less than 0.3 , the geological structure could be considered to be 1-D, 2-D, or 2-D with distortion(Bahr, 1988). Figure 4 shows the $2 \mathrm{D}$ skewness values of the LMT data. The most 2D skewness values are greater than 0.3 in this paper, which indicate that the lithospheric mantle of Antarctica has a three-dimensional (3D) resistivity structure.

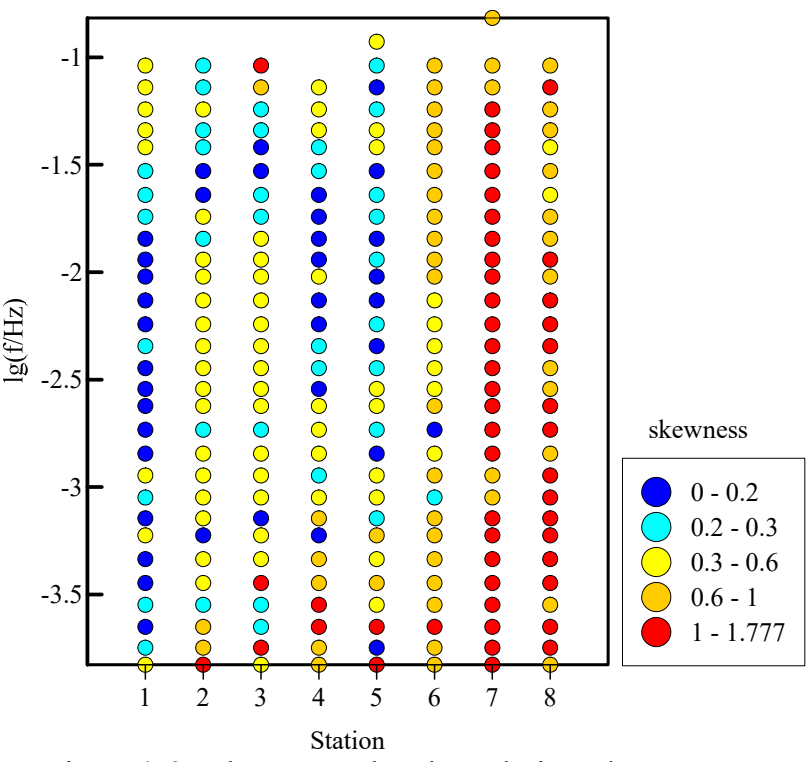

Figure 4. 2D skewness values by Bahr impedance tensor decomposition technique. The most $2 \mathrm{D}$ skewness values are greater than 0.3 .

The geo-electrical strike can indicate the geological structure strike(Bibby et al., 2005). In 2D model, it's the best azimuth of rotating impedance tensor to decompose MT data onto TE mode and TM mode(Zhang et al., 1987). Although the 2D skewness indicates that the underground of the study area has a 3D electrical structure, the geo-electrical strike is still helpful for us to understand the characteristics of the lithospheric mantle structure. Figure 5 shows the geo-electrical strike of the 2th and 6th LMT station with frequency. Since we take the X direction as the north-south direction, the geo-electrical strikes shift to the east-west direction with depth.
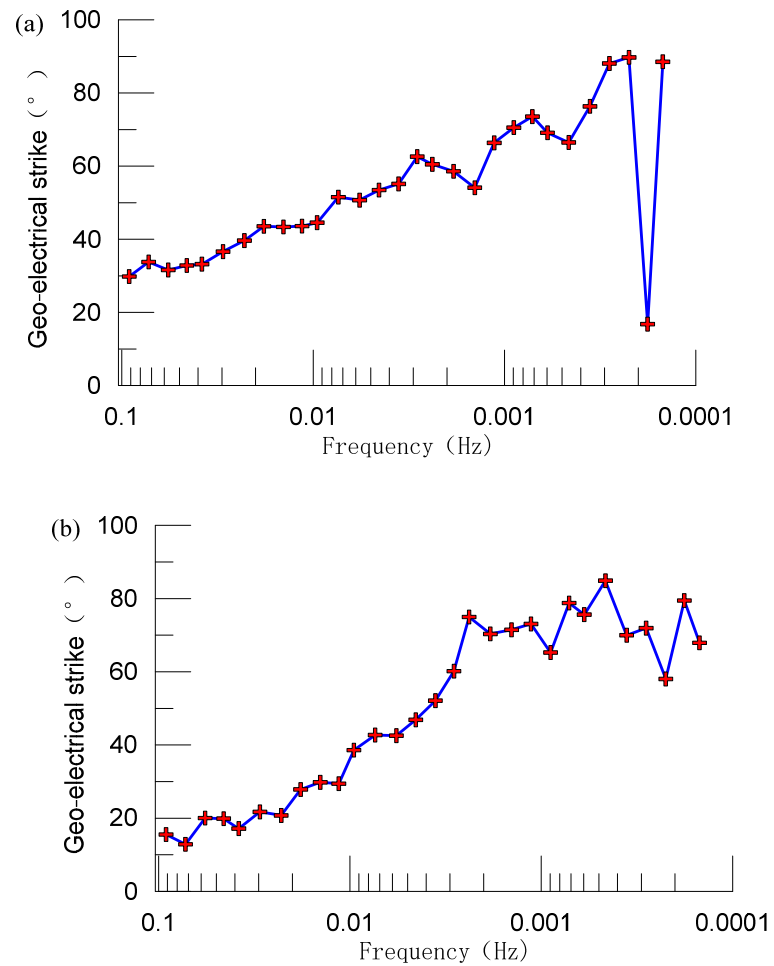

Figure 5. (a)The geo-electrical strike of the 2th LMT station with frequency; (b) The geo-electrical strike of the 6th LMT station with frequency. 
As the underground cannot be approximately $2 \mathrm{D}$ geoelectric model, the apparent resistivity of TE and TM modes cannot be separated. In this case, the equivalent impedance derived from the impedance invariants can better reflect the characteristics of the underground electrical structure than the single impedance to some extent(Rodríguez et al., 2001). Calculation formula for equivalent impedance:

$$
Z_{e f f}=\sqrt{Z_{x x} Z_{y y}-Z_{x y} Z_{y x}}
$$

The equivalent apparent resistivity can be calculated by Equation(4) (Shown in Figure 6).

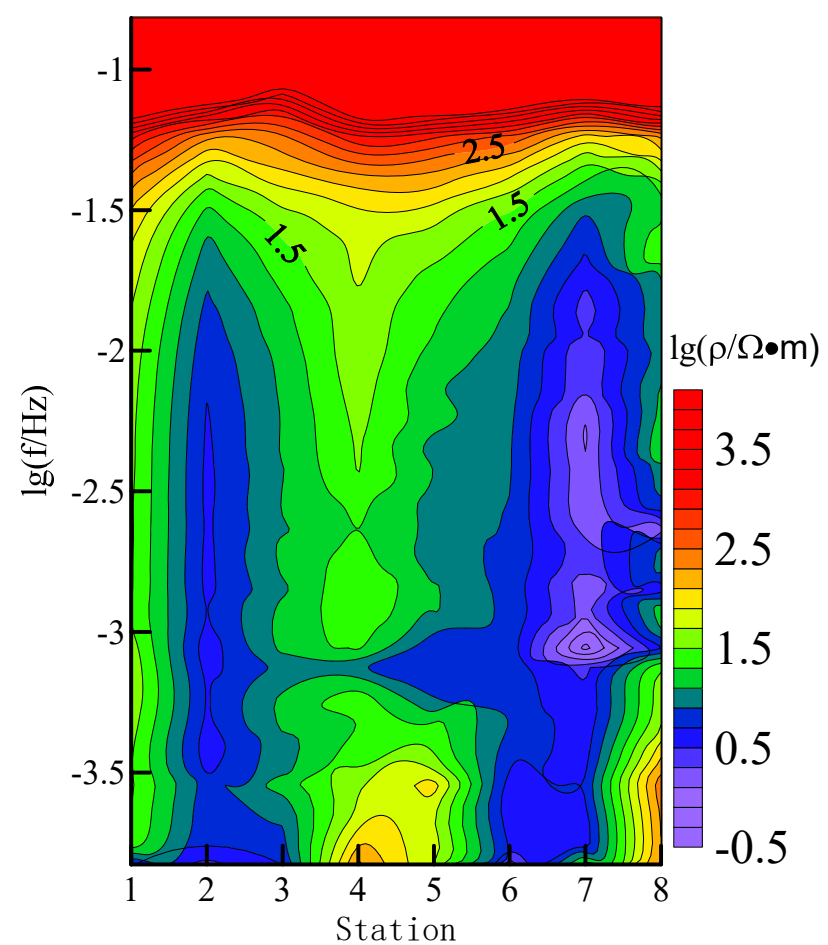

Figure 6. Equivalent apparent resistivity section

In this paper, 1D Occam inversion method is used for inversion of equivalent apparent resistivity (Shown in Figure

7 )(Rodríguez et al., 2001). The most interpretation depth is $90 \mathrm{~km}$. In the inverted section, there is a high conductivity layer (C1) at the depth of about $20 \mathrm{kms}$ which also was found in the MT exploration by Peacock and others at Antarctica(Armadillo et al., 2004; Murthy et al., 2013; Peacock and Selway, 2016). Armadillo et al. (2004) believed that this high conductivity layer is related to the thermal activities of the lower crust and upper mantle. In Figure 7, the thickness of high conductivity layer $\mathrm{C} 1$ is about $10 \mathrm{~km}$, but it is not an isolated abnormal layer. The vertical zonal distribution of high conductivity region (C2) intersects with $\mathrm{C} 1$ and extend to the bottom of inverted section which may be a channel for upward transportation of thermal materials. We thought that the $\mathrm{C} 1$ high conductivity layer is related to the underground thermal activity, and the high temperature leads to the extremely low resistivity; the $\mathrm{C} 2$ high conductivity region is related to the mantle thermal supply, which provides the heat source guarantee for the $\mathrm{C} 1 \mathrm{high}$ conductivity layer to maintain a high thermal state. Objectively speaking, because of the frequency less than $0.1 \mathrm{~Hz}$, there is a certain error in the burial depth of the high conductivity layer due to the lack of high frequency data.

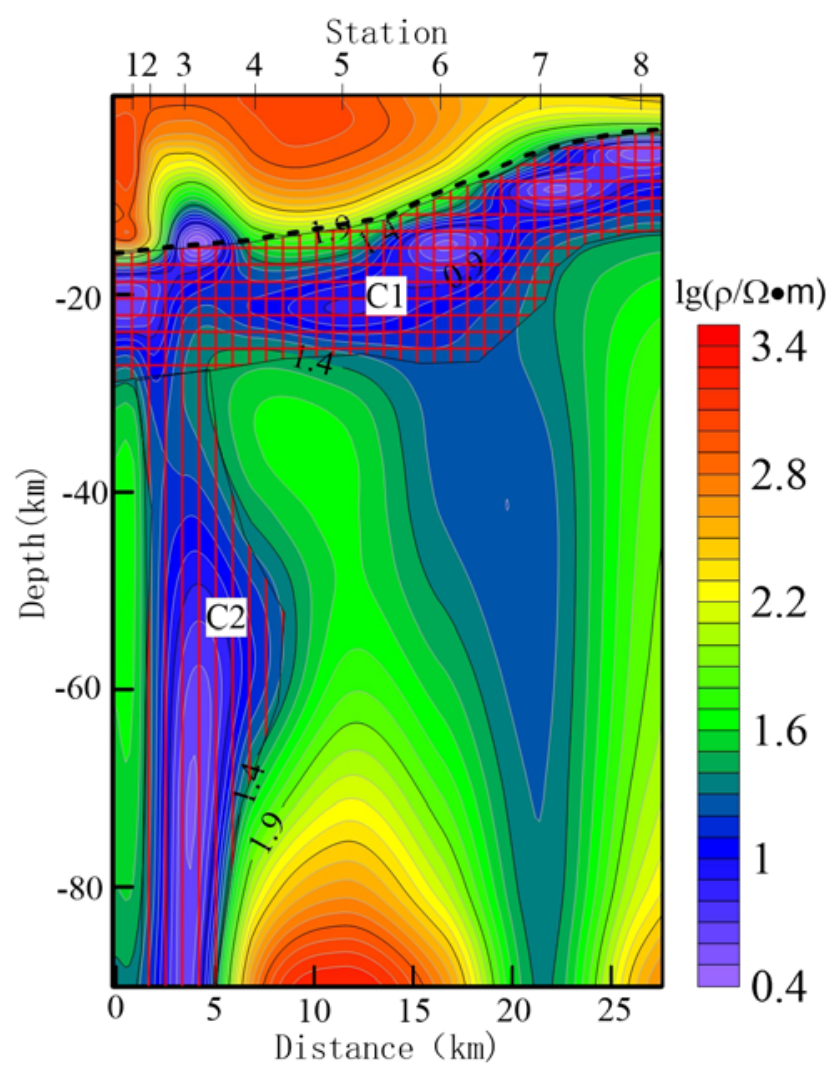

Figure 7. 1D Occam inverted section used equivalent apparent resistivity data. $\mathrm{C} 1$ and $\mathrm{C} 2$ are the abnormal area of high conductivity.

\section{CONCLUSIONS}

In this paper, LMT measurement has been successfully carried at the eastern Antarctic by Polar Research Institute of China. The 2D skewness of LMT data indicates that the lithospheric mantle of Antarctica has a 3D resistivity structure. The geoelectrical strikes to rotate around north-south to east-west with depth. The inverted section shows that there are high conductive regions in the lower crust of the Antarctic plate which is related to the thermal activities of the lower crust and upper mantle. The LMT measurement is feasible at the Antarctic, and the LMT has great potential for the exploration of the Antarctic plate crust and lithospheric mantle structure. In the future work, we plan to supplement the high-frequency MT data and extend the LMT survey line of the Antarctic inland, so as to obtain more abundant data.

\section{ACKNOWLEDGEMENTS}

This work is supported by the Natural Science Foundation of China (41876227) and National key R\&D Program of China(2018YFB1307504).

\section{REFERENCES}

An, M., Wiens, D.A., Zhao, Y., Feng, M., Nyblade, A.A., Kanao, M., Li, Y., Maggi, A., Lévêque, J.-J., 2015. S-velocity model and inferred Moho topography beneath the Antarctic Plate from Rayleigh waves. Journal of Geophysical Research: Solid Earth 120(1), 359-383.

Armadillo, E., Ferraccioli, F., Tabellario, G., Bozzo, E., 2004. Electrical structure across a major ice-covered fault belt in 
Northern Victoria Land (East Antarctica). Geophysical Research Letters 31(10).

Bahr, K., 1988. Interpretation of the magnetotelluric impedance tensor: regional induction and local telluric distortion. $J$. Geophys 62(2), 119-127.

Baranov, A., Tenzer, R., Bagherbandi, M., 2017. Combined Gravimetric-Seismic Crustal Model for Antarctica. Surveys in Geophysics 39(1), 23-56.

Beblo, M., Liebig, V., 1990. Magnetotelluric measurements in Antarctica. Physics of the Earth and Planetary Interiors 60(1-4), 89-99.

Bibby, H., Caldwell, T., Brown, C., 2005. Determinable and non-determinable parameters of galvanic distortion in magnetotellurics. Geophysical Journal International 163(3), 915-930.

Booker, J.R., 2014. The magnetotelluric phase tensor: a critical review. Surveys in Geophysics 35(1), 7-40.

Cande, S.C., Stock, J.M., Müller, R.D., Ishihara, T., 2000. Cenozoic motion between east and west Antarctica. Nature 404(6774), 145.

Chave, A.D., Jones, A.G., 2012. The magnetotelluric method: Theory and practice. Cambridge University Press.

Darbyshire, F.A., Dahl-Jensen, T., Larsen, T.B., Voss, P.H., Joyal, G., 2018. Crust and uppermost-mantle structure of Greenland and the Northwest Atlantic from Rayleigh wave group velocity tomography. Geophysical Journal International 212(3), 1546-1569.

Haeger, C., Kaban, M., Tesauro, M., Petrunin, A., Mooney, W., 2019. 3- D density, thermal, and compositional model of the Antarctic lithosphere and implications for its evolution. Geochemistry, Geophysics, Geosystems 20(2), 688-707.

Heeszel, D.S., Wiens, D.A., Anandakrishnan, S., Aster, R.C., Dalziel, I.W.D., Huerta, A.D., Nyblade, A.A., Wilson, T.J., Winberry, J.P., 2016. Upper mantle structure of central and West Antarctica from array analysis of Rayleigh wave phase velocities. Journal of Geophysical Research: Solid Earth 121(3), 1758-1775.

Hessler, V., Jacobs, J., 1966. A telluric current experiment on the Antarctic ice cap. Nature 210(5032), 190.

Ji, F., Li, F., Gao, J.-Y., Zhang, Q., Hao, W.-F., 2018. 3-D density structure of the Ross Sea basins, West Antarctica from constrained gravity inversion and their tectonic implications. Geophysical Journal International 215(2), 1241-1256.

Lilley, F., 1998. Magnetotelluric tensor decomposition: Part I, Theory for a basic procedure. Geophysics 63(6), 1885-1897.

Lizarralde, D., Chave, A., Hirth, G., Schultz, A., 1995. Northeastern Pacific mantle conductivity profile from longperiod magnetotelluric sounding using Hawaii- to- California submarine cable data. Journal of Geophysical Research: Solid Earth 100(B9), 17837-17854.
Mackie, R.L., Bennett, B., Madden, T.R., 1988. Long-period magnetotelluric measurements near the central California coast: a land-locked view of the conductivity structure under the Pacific Ocean. Geophysical Journal International 95(1), 181194.

Malleswari, D., Veeraswamy, K., Abdul Azeez, K.K., Gupta, A.K., Babu, N., Patro, P.K., Harinarayana, T., 2019. Magnetotelluric investigation of lithospheric electrical structure beneath the Dharwar Craton in south India: Evidence for mantle suture and plume-continental interaction. Geoscience Frontiers.

Martí, A., 2014. The role of electrical anisotropy in magnetotelluric responses: From modelling and dimensionality analysis to inversion and interpretation. Surveys in Geophysics $35(1), 179-218$.

Michaux, B., 2009. Reciprocality between biology and geology: Reconstructing polar Gondwana. Gondwana Research 16(3-4), 655-668.

Murthy, D.N., Veeraswamy, K., Harinarayana, T., Singh, U.K., Santosh, M., 2013. Electrical structure beneath Schirmacher Oasis, East Antarctica: a magnetotelluric study. Polar Research 32(1), 17309.

Peacock, J.R., Selway, K., 2016. Magnetotelluric investigation of the Vestfold Hills and Rauer Group, East Antarctica. Journal of Geophysical Research: Solid Earth 121(4), 2258-2273.

Ritzwoller, M.H., Shapiro, N.M., Levshin, A.L., Leahy, G.M., 2001. Crustal and upper mantle structure beneath Antarctica and surrounding oceans. Journal of Geophysical Research: Solid Earth 106(B12), 30645-30670.

Rodríguez, O.D., Enríquez, O.C., Fucugauchi, J.U., Arzate, J.A., 2001. Occam and Bostick 1-D inversion of magnetotelluric soundings in the Chicxulub impact crater, Yucatan, Mexico. Geofisica Internacional 40(4), 271-283.

Schaa, R., Harris, B., Pethick, A., Costall, A., Pigois, J.-P., Takougang, E.T., 2018. Magnetotelluric Inversion for Characterisation of Complex Aquifer Systems. ASEG Extended Abstracts 2018(1), 1-6.

Scheinert, M., Ferraccioli, F., Schwabe, J., Bell, R., Studinger, M., Damaske, D., Jokat, W., Aleshkova, N., Jordan, T., Leitchenkov, G., Blankenship, D.D., Damiani, T.M., Young, D., Cochran, J.R., Richter, T.D., 2016. New Antarctic Gravity Anomaly Grid for Enhanced Geodetic and Geophysical Studies in Antarctica. Geophys Res Lett 43(2), 600-610.

Sutherland, R., Cooper, A., 2008. The significance of Antarctica for studies of global geodynamics. Antarctica: A Keystone in a Changing World, 115-124.

Tenzer, R., Chen, W., Baranov, A., Bagherbandi, M., 2018. Gravity Maps of Antarctic Lithospheric Structure from RemoteSensing and Seismic Data. Pure and Applied Geophysics 175(6), 2181-2203.

Tian, Y., Zhu, H., Zhao, D., Liu, C., Feng, X., Liu, T., Ma, J., 2016. Mantle transition zone structure beneath the Changbai volcano: Insight into deep slab dehydration and hot upwelling near the $410 \mathrm{~km}$ discontinuity. Journal of Geophysical Research: Solid Earth 121(8), 5794-5808. 
Torsvik, T.H., Steinberger, B., Gurnis, M., Gaina, C., 2010. Plate tectonics and net lithosphere rotation over the past $150 \mathrm{My}$. Earth and Planetary Science Letters 291(1-4), 106-112.

Unsworth, M., Jones, A.G., Wei, W., Marquis, G., Gokarn, S., Spratt, J., 2005. Crustal rheology of the Himalaya and Southern Tibet inferred from magnetotelluric data. Nature 438(7064), 7881 .

Wannamaker, P.E., Stodt, J.A., Olsen, S.L., 1996. Dormant state of rifting below the Byrd Subglacial Basin, West Antarctica, implied by magnetotelluric (MT) profiling. Geophysical Research Letters 23(21), 2983-2986.

Wannamaker, P.E., Stodt, J.A., Pellerin, L., Olsen, S.L., Hall, D.B., 2004. Structure and thermal regime beneath the South Pole region, East Antarctica, from magnetotelluric measurements. Geophysical Journal International 157(1), 3654.

Winberry, J.P., Anandakrishnan, S., 2004. Crustal structure of the West Antarctic rift system and Marie Byrd Land hotspot. Geology 32(11), 977.

Zhang, P., Roberts, R., Pedersen, L., 1987. Magnetotelluric strike rules. Geophysics 52(3), 267-278. 